\title{
Perioperative outcomes and adverse events of minimally invasive versus open posterior lumbar fusion: meta-analysis and systematic review
}

\author{
Christina L. Goldstein, MD, FRCSC, ${ }^{1}$ Kevin Macwan, BHSc, ${ }^{2}$ Kala Sundararajan, MSc, ${ }^{2}$ and \\ Y. Raja Rampersaud, MD, FRCSC²
}

Divisions of ${ }^{1}$ Neurosurgery and ${ }^{2}$ Orthopedics, Toronto Western Hospital, University of Toronto, Ontario, Canada

OBJECT The objective of this study was to determine the clinical comparative effectiveness and adverse event rates of posterior minimally invasive surgery (MIS) compared with open transforaminal or posterior lumbar interbody fusion (TLIF/PLIF).

METHODS A systematic review of the Medline, EMBASE, PubMed, Web of Science, and Cochrane databases was performed. A hand search of reference lists was conducted. Studies were reviewed by 2 independent assessors to identify randomized controlled trials (RCTs) or comparative cohort studies including at least 10 patients undergoing MIS or open TLIF/PLIF for degenerative lumbar spinal disorders and reporting at least 1 of the following: clinical outcome measure, perioperative clinical or process measure, radiographic outcome, or adverse events. Study quality was assessed using the Grades of Recommendation, Assessment, Development, and Evaluation (GRADE) protocol. When appropriate, a meta-analysis of outcomes data was conducted.

RESULTS The systematic review and reference list search identified 3301 articles, with 26 meeting study inclusion criteria. All studies, including $1 \mathrm{RCT}$, were of low or very low quality. No significant difference regarding age, sex, surgical levels, or diagnosis was identified between the 2 cohorts (856 patients in the MIS cohort, 806 patients in the open cohort). The meta-analysis revealed changes in the perioperative outcomes of mean estimated blood loss, time to ambulation, and length of stay favoring an MIS approach by $260 \mathrm{ml}(p<0.00001), 3.5$ days $(p=0.0006)$, and 2.9 days $(p<$ $0.00001)$, respectively. Operative time was not significantly different between the surgical techniques $(p=0.78)$. There was no significant difference in surgical adverse events $(p=0.97)$, but MIS cases were significantly less likely to experience medical adverse events (risk ratio [MIS vs open] $=0.39,95 \%$ confidence interval $0.23-0.69, p=0.001$ ). No difference in nonunion $(p=0.97)$ or reoperation rates $(p=0.97)$ was observed. Mean Oswestry Disability Index scores were slightly better in the patients undergoing MIS $(n=346)$ versus open TLIF/PLIF $(n=346)$ at a median follow-up time of 24 months (mean difference [MIS - open] $=3.32, p=0.001$ ).

CONCLUSIONS The result of this quantitative systematic review of clinical comparative effectiveness research examining MIS versus open TLIF/PLIF for degenerative lumbar pathology suggests equipoise in patient-reported clinical outcomes. Furthermore, a meta-analysis of adverse event data suggests equivalent rates of surgical complications with lower rates of medical complications in patients undergoing minimally invasive TLIF/PLIF compared with open surgery. The quality of the current comparative evidence is low to very low, with significant inherent bias.

http://thejns.org/doi/abs/10.3171/2015.2.SPINE14973

KEY WORDS lumbar spine fusion; minimally invasive spine surgery; comparative effectiveness; adverse events; systematic review; meta-analysis

ABBREVIATIONS Cl = confidence interval; EBL = estimated blood loss; GRADE = Grades of Recommendation, Assessment, Development, and Evaluation; LOS = length of stay; MIS = minimally invasive surgery; ODI = Oswestry Disability Index; OR = operating room; PLIF = posterior lumbar interbody fusion; RCT = randomized controlled trial; $\mathrm{RR}=$ risk ratio; $\mathrm{SSI}=$ surgical site infection; TLIF = transforaminal lumbar interbody fusion; VAS = visual analog scale.

ACCOMPANYING EDITORIAL See pp 413-415. DOI: 10.3171/2015.3.SPINE15238.

SUBMITTED September 24, 2014. ACCEPTED February 26, 2015.

INCLUDE WHEN CITING Published online November 13, 2015; DOI: 10.3171/2015.2.SPINE14973. 
$\mathrm{L}$ UMBAR spinal fusion is widely accepted as a method of treatment of many spinal conditions, including those of a degenerative nature. ${ }^{2}$ While demands for spinal fusion procedures have increased as a result of the rising percentage of adults over the age of $65,{ }^{26}$ the morbidity associated with open fusion procedures, including substantial blood loss,${ }^{5}$ increased complication rates, ${ }^{4}$ and longer hospital stays, ${ }^{50}$ may expose this patient population to undesirable levels of surgical risk.

Minimally invasive surgical techniques are increasingly being applied to the field of spine surgery after demonstrating improved clinical outcomes and decreased perioperative morbidity in the fields of general surgery, gynecology, and urology. ${ }^{12,33,51}$ Minimally invasive lumbar fusion has also been shown to be safe and effective in treating lumbar pathology in elderly patients. ${ }^{8}$ However, issues relating to a significant learning curve associated with minimally invasive lumbar fusion have arisen, including increased operative times and higher complication rates, ${ }^{22-24,38,43,46}$ and concerns persist regarding inadequate neural element decompression during minimally invasive lumbar fusion, resulting in persistent symptoms and a need for reoperation. ${ }^{24}$

Multiple recent reports have examined the clinical outcomes of and complications associated with minimally invasive surgery (MIS) versus open posterior lumbar fusion. ${ }^{11,19,20,27,36,60}$ However, these investigations have involved qualitative reviews or meta-analyses of primarily noncomparative cohorts or analyses of national database records, ${ }^{27}$ the results of which are subject to multiple sources of bias. Thus, the true outcomes and complication rates of open versus minimally invasive transforaminal or posterior lumbar interbody fusion (TLIF/PLIF) remain unknown.

The primary objective of this systematic review and meta-analysis, therefore, is to describe the perioperative process measures and complication rates associated with open versus minimally invasive TLIF/PLIF. Secondarily, we intend to quantitatively summarize data pertaining to patient-reported outcomes, fusion, and reoperation rates in cohorts of patients undergoing open versus minimally invasive posterior lumbar fusion for degenerative disorders. We hypothesize that the current evidence will suggest equivalent clinical outcomes and no differences in adverse event rates between open and MIS cohorts.

\section{Methods}

\section{Systematic Review and Data Collection}

Guidelines proposed by the Meta-analysis of Observational Studies in Epidemiology (MOOSE) Group ${ }^{49}$ and the Preferred Reporting Items for Systematic Reviews and Meta-analyses (PRISMA) statement ${ }^{30}$ were consulted prior to undertaking our systematic review. The exact methods used during our literature search have been described elsewhere. ${ }^{15}$ Briefly, our research coordinator with training in systematic reviews performed an electronic search of Medline, EMBASE, Web of Science, and Cochrane databases from database inception to May 2012 using derivatives of the following Medical Subject Headings (MeSH): "minimally invasive"/"minimal access" and "lumbar spine"/“"lumbar vertebrae" or "fusion"/"surgical procedures." Only English-language citations were included. Potential articles were imported into the online reference management program RefWorks (RefWorks-COS, ProQuest, LLC), and duplicate citations were removed.

Study titles, abstracts, and full-text articles were then screened by 2 independent reviewers (C.L.G. and K.M.). Included citations were randomized controlled trials (RCTs) or cohort studies comparing posterior open and minimally invasive fusion for degenerative lumbar pathology in at least 10 patients per study arm and reporting at least 1 of the following types of outcomes: 1) clinical, 2) process measure, 3) radiographic, or 4) complications. Both reviewers also performed an independent PubMed search using the phrase "minimally invasive spine surgery" and a manual search of reference lists of included articles to ensure relevant studies were not missed by the electronic literature search. The senior author (Y.R.R.) was involved in decisions regarding study eligibility in cases of disagreement.

The study reviewers then used a custom data extraction form to extract relevant study data in duplicate. Data elements extracted included methodology data to confirm study eligibility, study design, patient demographics, performed interventions, outcomes of interest, statistical methods, and study results. One reviewer (K.M.) then entered extracted data into a spreadsheet (Microsoft Excel 1997-2004, Microsoft Corp.) with accuracy of data entry confirmed by the second reviewer (C.L.G.).

\section{Rating of Study Quality}

The methodological quality of the included studies was then independently assessed by 2 reviewers (C.L.G. and Y.R.R.) according to the Grades of Recommendation, Assessment, Development, and Evaluation (GRADE) protocol. ${ }^{3}$ Information pertaining to study design, study limitations, consistency of results, directness of evidence, and study precision was extracted from each paper, and based on this information, the overall quality of each study was rated as high, moderate, low, or very low. In cases of disagreement, the 2 reviewers arrived at the final GRADE rating through discussion.

\section{Comparison of MIS and Open Cohorts}

Mean values for age, sex (\% male), number of surgical levels, and preoperative diagnoses were calculated for those studies reporting on patient demographics. Betweengroup comparisons were performed using a 2-sample t-test for continuous variables, a 2-proportion z-test for number of surgical levels, and a chi-square test of independence for preoperative diagnosis. A p value $<0.05$ was considered statistically significant.

\section{Meta-Analysis of Clinical Outcomes}

Study heterogeneity was assessed using the Q test, the $\mathrm{I}^{2}$ statistic, and the $\tau^{2}$ statistic. If the calculated $\mathrm{Q}$ was less than a critical value found in a chi-square table, we accepted the hypothesis that all studies have the same "true" effect size (i.e., there is a lack of heterogeneity). ${ }^{31}$ The $\mathrm{I}^{2}$ statistic represents the proportion of the variabil- 
ity in the results due to true study heterogeneity versus chance and is interpreted as the heterogeneity being absent $\left(\mathrm{I}^{2}=0-25 \%\right)$, low $\left(\mathrm{I}^{2}=25.1 \%-50 \%\right)$, moderate $\left(\mathrm{I}^{2}=\right.$ $50.1 \%-75 \%)$ or high $\left(\mathrm{I}^{2}=75.1 \%-100 \%\right){ }^{17}$ The $\tau^{2}$ statistic is an estimate of between-study variance in which a value greater than 1 suggests the presence of substantial heterogeneity between studies. ${ }^{31}$

For continuous variables, a pooled estimate of treatment effect was calculated as the mean difference and 95\% confidence interval (CI) between outcomes in the MIS and open cohorts using an inverse-variance weighting method with a random effects model. For comparison of the results of dichotomous variables (i.e., complications), a risk ratio (RR) and 95\% $\mathrm{CI}$ were calculated using a Mantel-Haenszel method with a random effects model. The random effects model, as opposed to a fixed-effects model, provides a more conservative estimate of treatment effect? ${ }^{7}$ This statistical approach was believed to be appropriate given the presumed heterogeneity between the trials. The program Review Manager 5.1 (The Nordic Cochrane Centre, The Cochrane Collaboration) was used to calculate the individual and pooled statistics. Forest plots were constructed to graphically display the results of the individual studies and pooled estimates of effect.

\section{Results}

\section{Search Results}

Our electronic database search yielded 4350 studies, of which 2824 were excluded as duplicates. A further 1775 studies were identified in the PubMed search. After review of titles, abstracts, and full-text articles, 3277 studies were excluded based on our aforementioned inclusion criteria. Manual searching of reference lists found 5 publications not previously included, although this resulted in the exclusion of 3 studies reporting on a duplicate cohort of patients. Thus, 26 citations remained for study inclusion (Fig. 1).

\section{Characteristics and Quality of Included Studies}

Of these 26 studies, only 1 prospective RCT was iden-

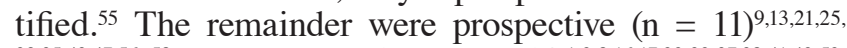

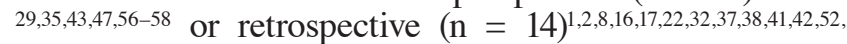
54,59 comparative cohort studies (Table 1). A funnel plot of the results of RR for all complications in the MIS cohorts compared with the open cohorts illustrates symmetric distribution of the studies, suggesting a lack of publication bias (Fig. 2).

With the exception of the single prospective RCT by Wang et al ${ }^{58}$ that was rated initially as high quality, all of the studies started with a quality rating of low according to the GRADE protocol. Methodological flaws resulting in downgrading of study quality were identified in all the included studies. Due to failure to report on the consecutive or nonconsecutive nature of patient enrollment, blinding, allocation concealment, and the nature of the data analysis (i.e., intention to treat vs as treated), the single prospective RCT was given a quality rating of low. ${ }^{58}$ Two of the prospective cohort studies retained their low quality rating ${ }^{27,57}$ while the 9 others were downgraded to very low quality. ${ }^{9} 13,21,29,35,43,47,56,58$ Similar ratings were given to the retrospective comparative cohort studies with $4^{1,41,42,56}$ and $10^{2,8,16,17,22,32,37,38,52,59}$ graded as low and very low quality, respectively.

\section{Patient Demographics}

The MIS and open cohorts in the 26 studies enrolled 856 and 806 patients, respectively. No statistically significant difference was identified between the open and MIS cohorts with respect to mean age, sex, and number of levels fused (Table 2). Similarly, when analyzed in aggregate, there was no significant difference between the cohorts with respect to the proportion of patients in each diagnostic category, although significant diagnostic heterogeneity was observed in more than half of the studies (Table 1). $2,8,9,22,25,29,35,37,42,43,47,54-56,58,59$

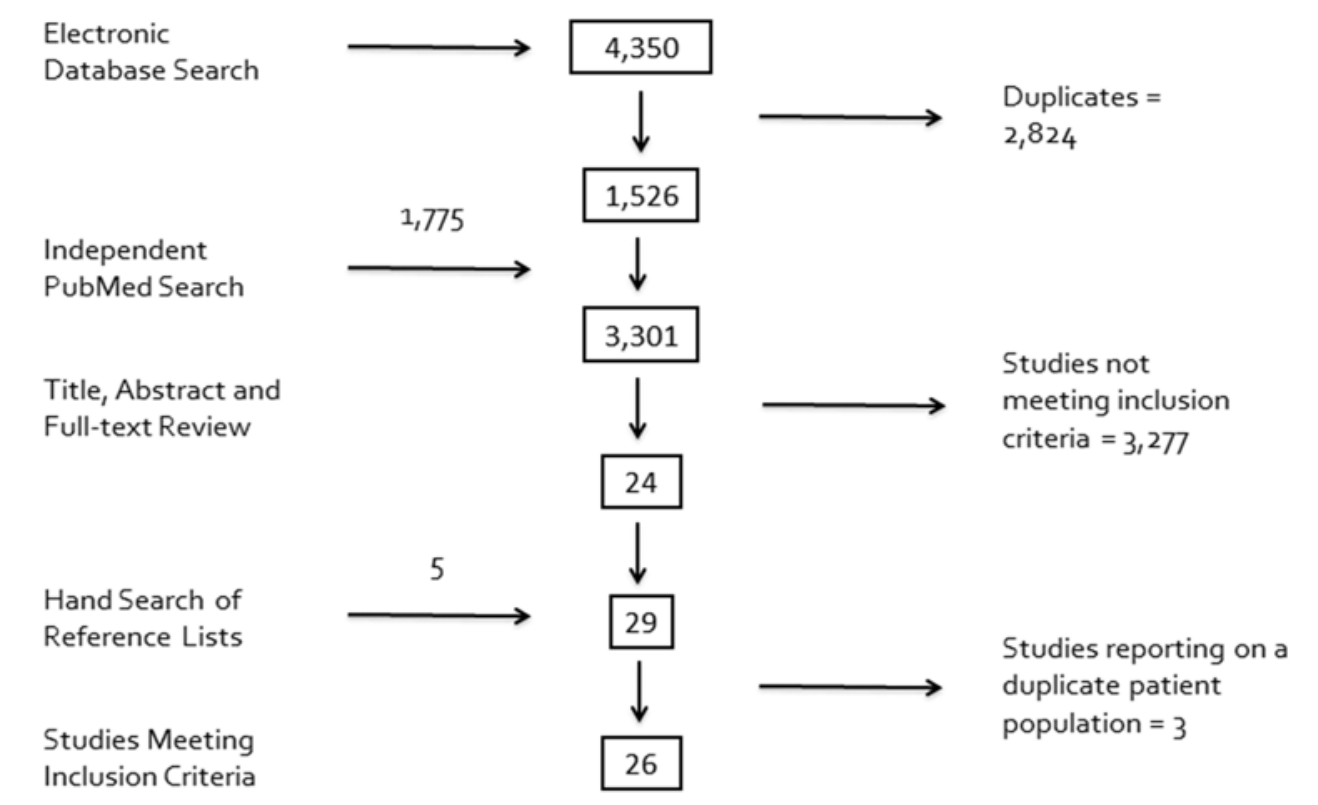

FIG. 1. Systematic review results of study identification and exclusion. 


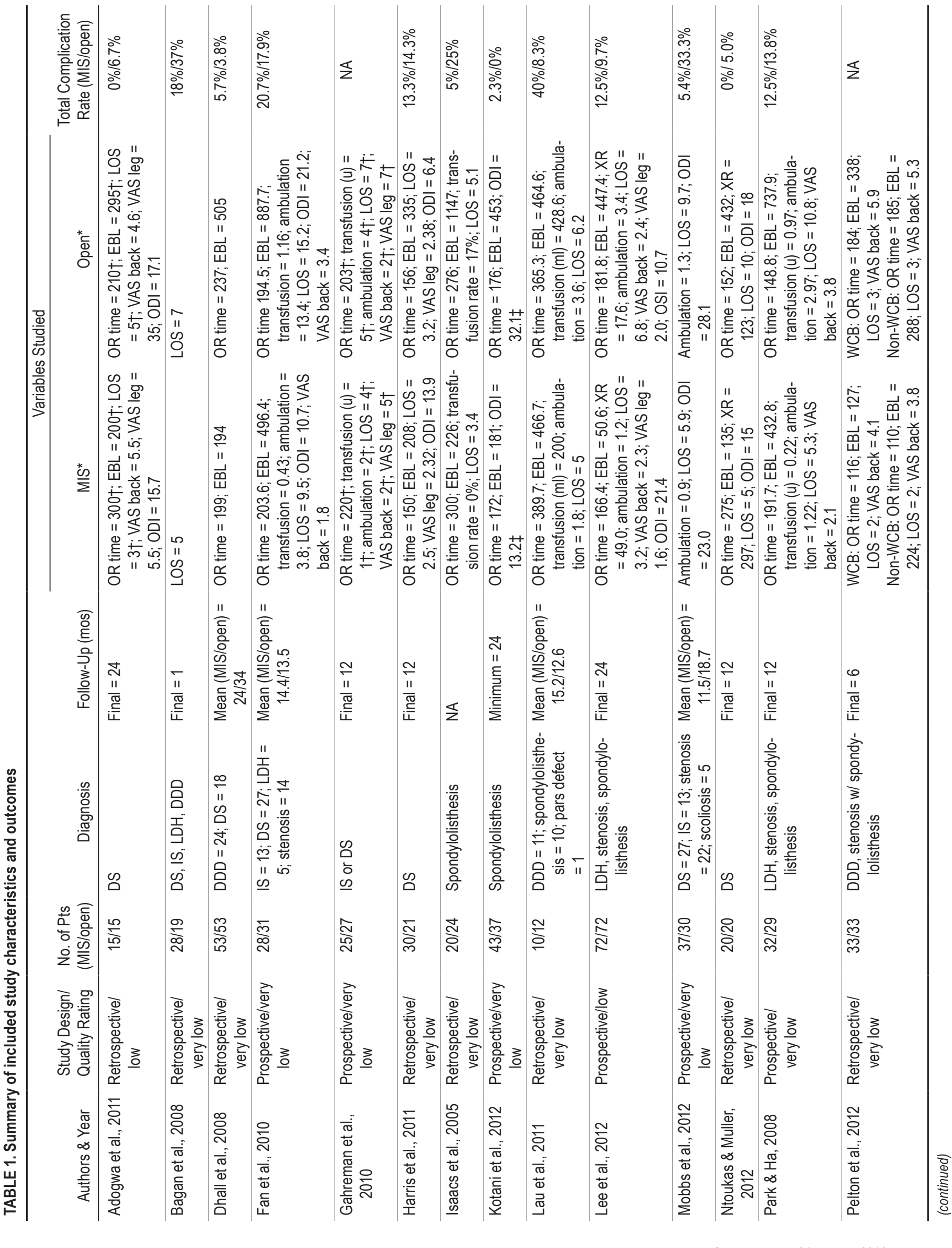




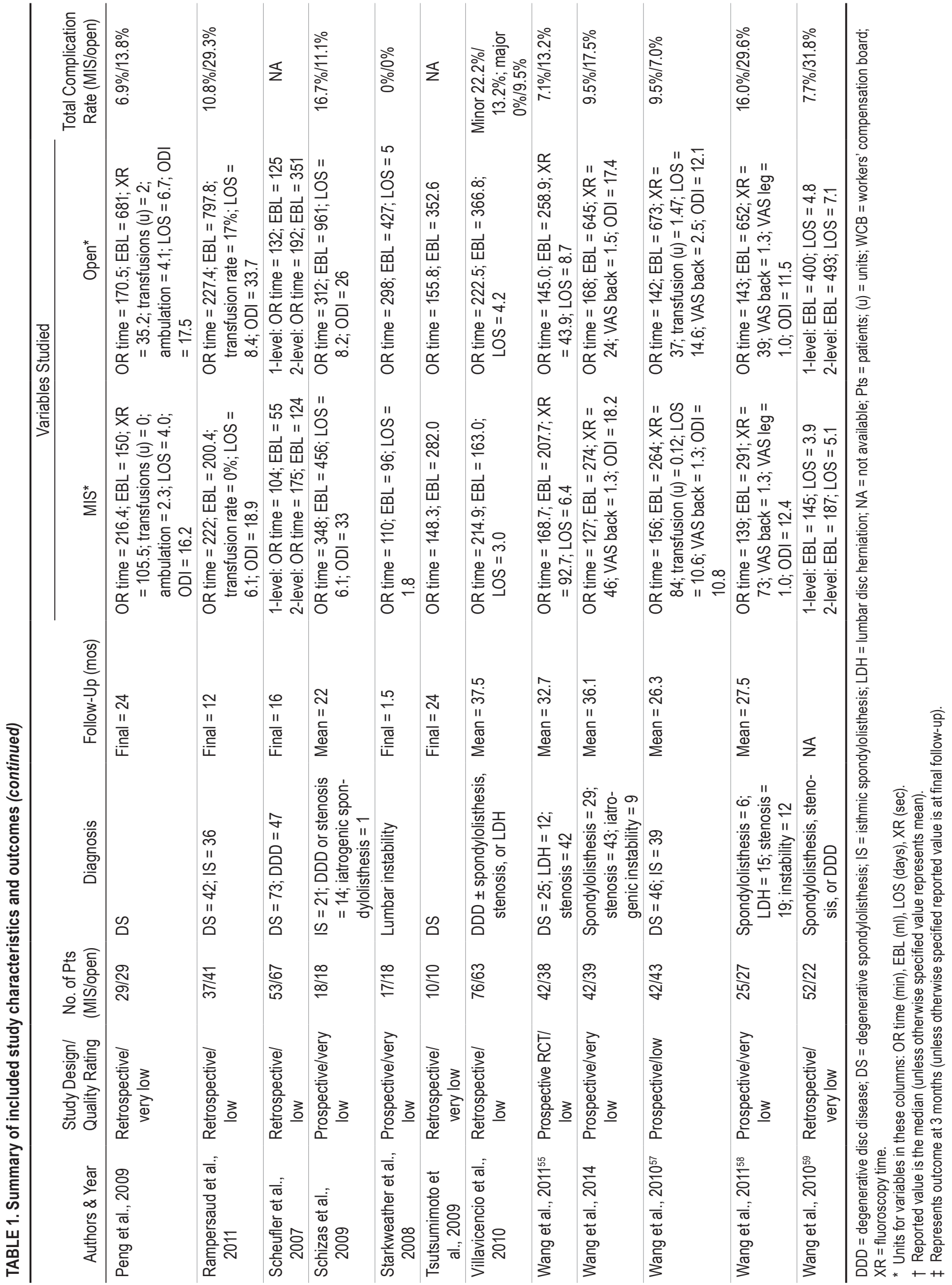




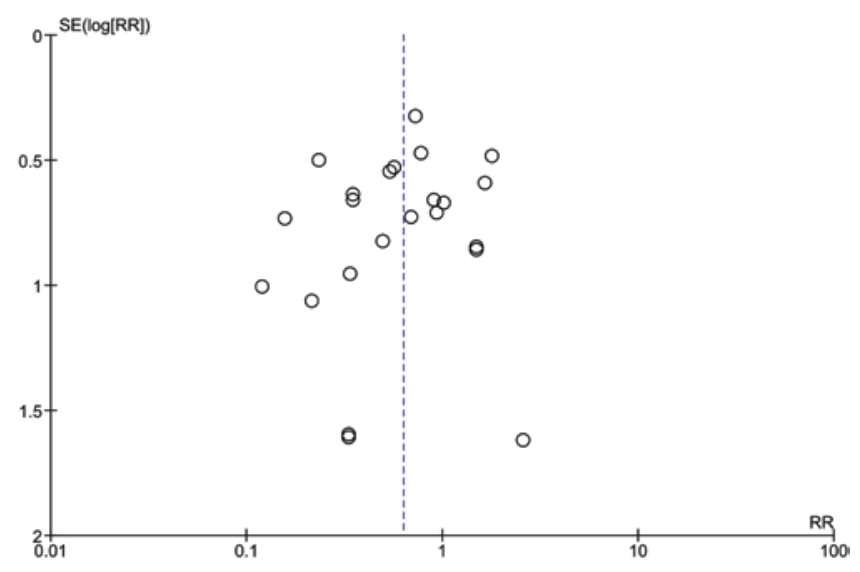

FIG. 2. Funnel plot of RRs for any complication in the MIS versus open cohorts. SE = standard error. Figure is available in color online only.

\section{Clinical Outcomes}

With regard to intraoperative measures, no significant difference in operating room (OR) time was identified between the open and MIS cohorts (mean difference [MIS - open] $=-2.49 \pm 17.17$ minutes, $\mathrm{p}=0.78$; Table 3). As expected, increased use of intraoperative fluoroscopy was required to perform MIS fusions, with a mean increase in fluoroscopy time of 55.9 seconds in MIS compared with open procedures (95\% CI 36.12-75.75, $\mathrm{p}<0.00001)$. Intraoperative estimated blood loss (EBL) was found to strongly favor minimally invasive fusion, with patients in the open cohort losing an average of $260 \mathrm{ml}$ more blood (95\% CI 187.54-332.69, $\mathrm{p}<0.00001)$.

In-hospital recovery was also positively impacted by a minimally invasive surgical approach. In the 4 studies examining postoperative time to ambulation, patients undergoing an MIS procedure were able to ambulate an average of 3.5 days faster than their open counterparts $(95 \%$ CI 1.51-5.52, $\mathrm{p}=0.0006)$. This translated into a shorter length of stay (LOS), with patients in the MIS groups being discharged a mean of 2.87 days earlier than those in the open arm (95\% CI 1.91-3.82, p < 0.00001).

At a median follow-up of 24 months the results of MIS and open surgery continued to be at least equivalent. No significant difference was found in change in visual analog scale (VAS) back or leg scores between the 2 cohorts (VAS back mean difference [MIS - open] $=-0.38 \pm 0.56$, $\mathrm{p}=0.19$; VAS leg mean difference $=0.63 \pm 1.0, \mathrm{p}=0.21$ ). However, a small but statistically significant difference in change in Oswestry Disability Index (ODI) scores favoring MIS surgery was identified, with patients in the experimental cohort demonstrating a 3.32-point larger improvement in ODI scores at final follow-up (95\% CI 1.33-5.32, $\mathrm{p}=0.001$; median follow-up 24 months).

\section{Complication Rates}

All but 2 of the 26 included studies reported complication rates as a study outcome, ${ }^{37,42}$ although the types of complications reported in the 24 studies were variable. No significant difference was identified between the cohorts with respect to rates of intraoperative dural tear (Fig. 3A), superficial or deep infections (Fig. 3B), or surgical complications (including graft or screw malposition, neurological deficit, or hematoma; Fig. 3C). No difference in reoperation rates for these types of complications was observed (RR [MIS vs open] =0.99 [95\% CI 0.40-2.44], p = 0.97; Fig. 4). Conversely, patients undergoing a minimally invasive fusion were on average $60 \%$ less likely than those in the open surgical group to experience a medical complication, including urinary tract infection, respiratory complications, cardiac complications, or need for transfusion (RR [MIS vs open] $=0.39$ [95\% CI 0.23-0.69], $\mathrm{p}=0.001$; Fig. 5). Regarding radiographic outcome, no significant difference was observed in union rates between the MIS and open cohorts (RR [MIS vs open] $=0.97$ [95\% CI 0.352.63], $\mathrm{p}=0.95$; Fig. 6). When all types of complications except reoperation were considered together, patients in the MIS cohort were almost $40 \%$ less likely than those undergoing open surgery to have a complication of any type $(\mathrm{RR}$ [MIS vs open] $=0.63$ [95\% CI 0.47-0.85], $\mathrm{p}=0.002)$.

\section{Discussion}

The first description of minimally invasive TLIF/PLIF appeared in the literature in $2003,{ }^{10}$ and since that time use of the technique has been gaining popularity. However, concerns remain regarding increased operative times and complication rates and poorer clinical outcomes associated with the learning curve of this technically demanding procedure. Although in our systematic review of comparative studies of open versus minimally invasive TLIF/PLIF for degenerative conditions we were unable to specifically examine these outcomes as they relate to surgeon experience and the surgical learning curve per se, more than a decade after Foley et al.'s initial report of their experience, ${ }^{10}$ a meta-analysis of the existing literature reveals minimally invasive TLIF/PLIF to be at least as effective as open surgery in terms of patient-reported clinical outcome, with no increase in operative times or surgical complications. Furthermore, patients undergoing minimally invasive fusion lose less blood than their open counterparts and are at significantly lower risk of experiencing a medical complication.

In 2009, Parker et al. ${ }^{36}$ conducted a systematic review of Medline regarding infection in open versus minimally invasive lumbar fusion. In contract to the results of our study, their examination of surgical site infections (SSIs) in 10 MIS cohorts and 20 open TLIF cohorts with 1133 patients found a significantly lower incidence of the rate of SSI in minimally invasive TLIF compared with open cohorts $(0.6 \%$ vs $4.0 \%$, respectively; $\mathrm{p}=0.005)$. Although the quality of the included studies was not assessed, the authors acknowledged the limitations of their meta-analysis of noncomparative Level IV studies, which likely explains the differences between their findings and those of our investigation, which included only comparative studies.

A similar study was conducted in 2010 to determine differences in fusion and complication rates between MIS and open TLIF. ${ }^{60}$ A systematic review of Medline identified 23 noncomparative studies enrolling 1028 patients and reporting on radiographic fusion rates. Again, the methodological quality of the included studies was not examined, but all were classified as Level III evidence. Similar to our study, no difference in fusion rates between the cohorts 
TABLE 2. Comparison of patient demographics between MIS and open cohorts

\begin{tabular}{|c|c|c|c|c|}
\hline Variable & No. of Studies $(n=26)$ & MIS $(n=856)$ & Open $(n=806)$ & $p$ Value \\
\hline Mean age (yrs) & 15 & 55.3 & 56.7 & $0.07^{*}$ \\
\hline Sex ( $\%$ female) & 22 & 59 & 56 & $0.12 \dagger$ \\
\hline Surgical level (\%)‡ & 24 & & & $0.44 \S$ \\
\hline 1-level & & 92 & 90 & \\
\hline 2-level & & 8 & 9 & \\
\hline Diagnosis (\%) & 14 & & & $0.25 \S$ \\
\hline Spinal stenosis & & 20 & 17 & \\
\hline Degenerative spondylolisthesis & & 40 & 42 & \\
\hline Isthmic spondylolisthesis & & 17 & 17 & \\
\hline Degenerative disc disease & & 15 & 13 & \\
\hline Other & & 7 & 11 & \\
\hline
\end{tabular}

was identified, with $90.9 \%$ of open and $94.8 \%$ of minimally invasive TLIF patients eventually attaining successful fusion. The authors further identified an increased complication rate in the open cohort compared with the MIS cohort (12.6\% vs $7.5 \%$, respectively), although the types of complications reported in the individual studies were not reported.

In a retrospective review of Premier Perspective Database hospital discharge and billing records, McGirt et al. ${ }^{27}$ used ICD-9-CM codes to identify 5170 patients undergoing posterior lumbar or lumbosacral fusion using a minimally invasive pedicle screw system. The diagnosis of infection was made, again using ICD-9-CM codes for postoperative infection or administration of parenteral antibiotics. No significant difference in SSI rates for 1-level fusions (MIS 4.5\% vs 4.8\%; $\mathrm{p}=0.77$ ) was found, although significantly fewer SSIs occurred in patients undergoing 2-level MIS fusions compared with open fusions (4.6\% vs $7.0 \%$, respectively; $p=0.037$ ). Although this is the largest examination of infection rates in open versus minimally invasive lumbar fusion, interpretation of the results of this study is limited by the use of ICD-9-CM codes to both identify patients and diagnose infection.

Karikari et al. ${ }^{20}$ also performed a systematic review of Medline in 2010, but in contrast to Wu et al., ${ }^{60}$ the authors were interested in operative times, complication rates, and patient-reported outcomes, and included both comparative and noncomparative studies. In the 7 comparative and 8 noncomparative studies included, VAS and ODI scores were found to increase in both cohorts, from $62 \%$ to $87.7 \%$ in MIS patients and $56.1 \%$ to $77 \%$ in open patients, with no significant difference in surgical time observed. Furthermore, complication rates ranged from $0 \%$ to $33.3 \%$ for minimally invasive TLIF compared with $1.6 \%-16.7 \%$ in the open TLIF/PLIF studies, although a meta-analysis of these results was not performed.

Most recently, Fourney et al. ${ }^{11}$ conducted a comprehensive systematic review of Medline, EMBASE, and the Cochrane Collaboration and reported a qualitative summary of blood loss, operating time, and complication rates in open versus minimally invasive spine surgery for lumbar discectomy, decompression, and instrumented fusion. In the 3 studies comparing operative time for MIS versus open fusion, 2 supported shorter operative times in MIS surgery ${ }^{35,43}$ while the third suggested faster OR times in MIS fusion. ${ }^{38}$ As with our investigation, all 3 studies showed lower blood loss in the MIS fusion versus open fusion cohorts. Complications, including dural tears, nerve injury, and infections, appeared somewhat higher in the MIS versus open cohorts (1.9\% vs $0 \%, 2.5 \%$ vs $1.2 \%$, and $1.8 \%$ vs $0.9 \%$, respectively), but no statistical comparison of the results was performed. The authors concluded that

TABLE 3. Summary of perioperative outcomes in MIS and open cohorts

\begin{tabular}{lcccc}
\hline \multicolumn{1}{c}{ Outcome } & No. of Studies & Participants & Mean Difference* $(95 \% \mathrm{Cl})$ & $\mathrm{p} \mathrm{Value}$ \\
\hline OR time (min) & 15 & 1016 & $-2.49(-19.66,14.68)$ & 0.78 \\
\hline LOS (days) & 13 & 891 & $-2.87(-3.82,-1.91)$ & $<0.00001$ \\
\hline EBL (ml) & 17 & 1091 & $-260.11(-332.69,-187.54)$ & $<0.00001$ \\
\hline XR time (sec) & 6 & 481 & $55.93(6.12,75.75)$ & $<0.00001$ \\
\hline Time to ambulation (days) & 4 & 330 & $-3.52(-5.52,-1.51)$ & 0.0006 \\
\hline Change in VAS back pain & 8 & 552 & $-0.38(-0.94,0.18)$ & 0.19 \\
\hline Change in VAS leg pain & 3 & 239 & $0.63(-0.37,1.63)$ & 0.21 \\
\hline Change in ODI Score & 10 & 692 & $-3.32(-5.32,-1.33)$ & 0.001 \\
\hline
\end{tabular}

\footnotetext{
${ }^{*}$ Mean difference $=$ MIS - open TLIF.
} 
A

Study or Subgroup Events Total Events Total Weight $\mathrm{M}-\mathrm{H}$, Random, $95 \% \mathrm{Cl}$ Bagan 2008 Dhall 2008

Harris 2011

Isaacs 2005

Lee 2012

Mobbs 2012

Ntoukas 2010

Rampersaud 2011

Schizas 2009

Villavicencio 2010

Wang $2010^{57}$

Wang $2010^{59}$ (1-level)

Wang $2010^{59}$ (2-level)

Wang $2011^{58}$

Wang 2014

Total $(95 \% \mathrm{Cl})$

Total events

$\begin{array}{lrrrr}0 & 28 & 3 & 19 & 4.3 \%\end{array}$

Risk Ratio

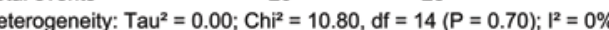

Test for overall effect: $Z=1.10(P=0.27)$

$0.10[0.01,1.80]$

$0.33[0.01,7.74]$

$1.40[0.14,14.46]$

$0.24[0.01,4.69]$

$3.00[0.12,72.44]$

$0.26[0.01,6.23]$

$0.33[0.01,7.72]$

$0.37[0.04,3.40]$

$3.00[0.13,69.09]$

$5.80[0.73,45.92]$

$1.02[0.15,6.94]$

$0.12[0.01,2.76]$

$0.88[0.07,11.54]$

$0.65[0.17,2.44]$

$0.62[0.11,3.51]$

$0.71[0.39,1.30]$

M-H, Random, $95 \% \mathrm{Cl}$

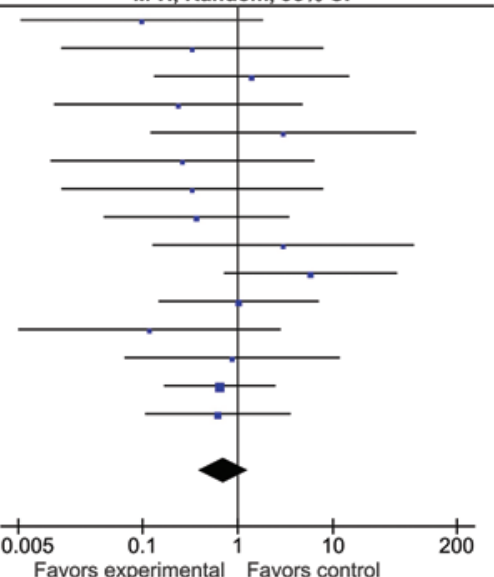

B

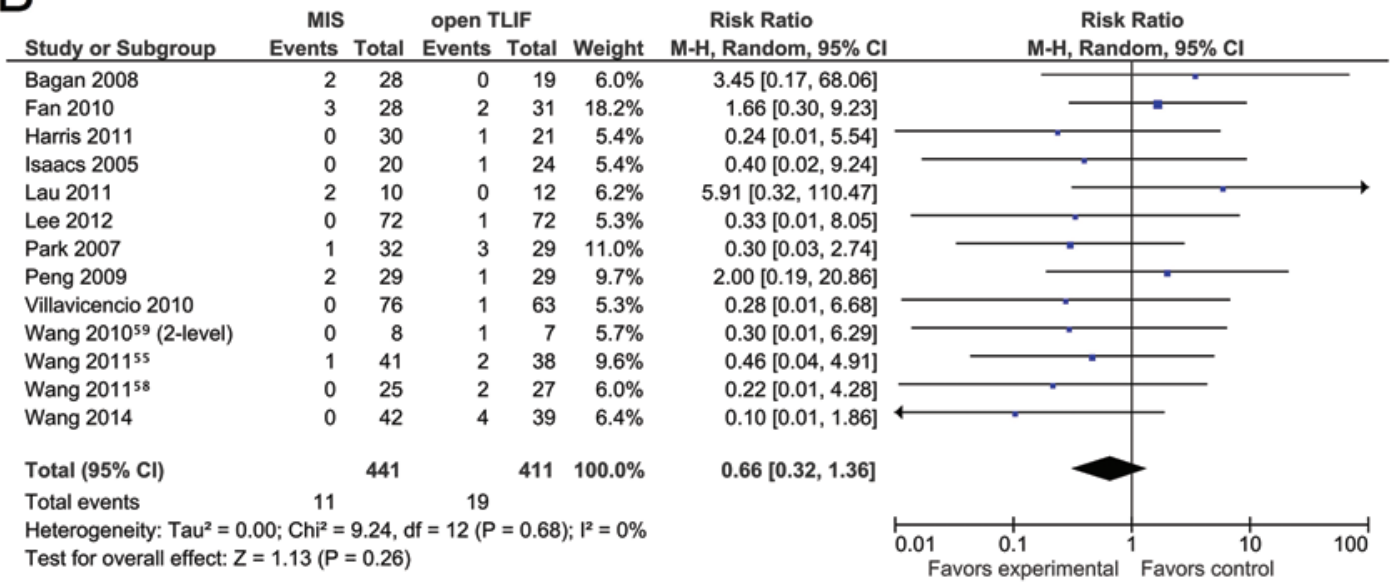

C

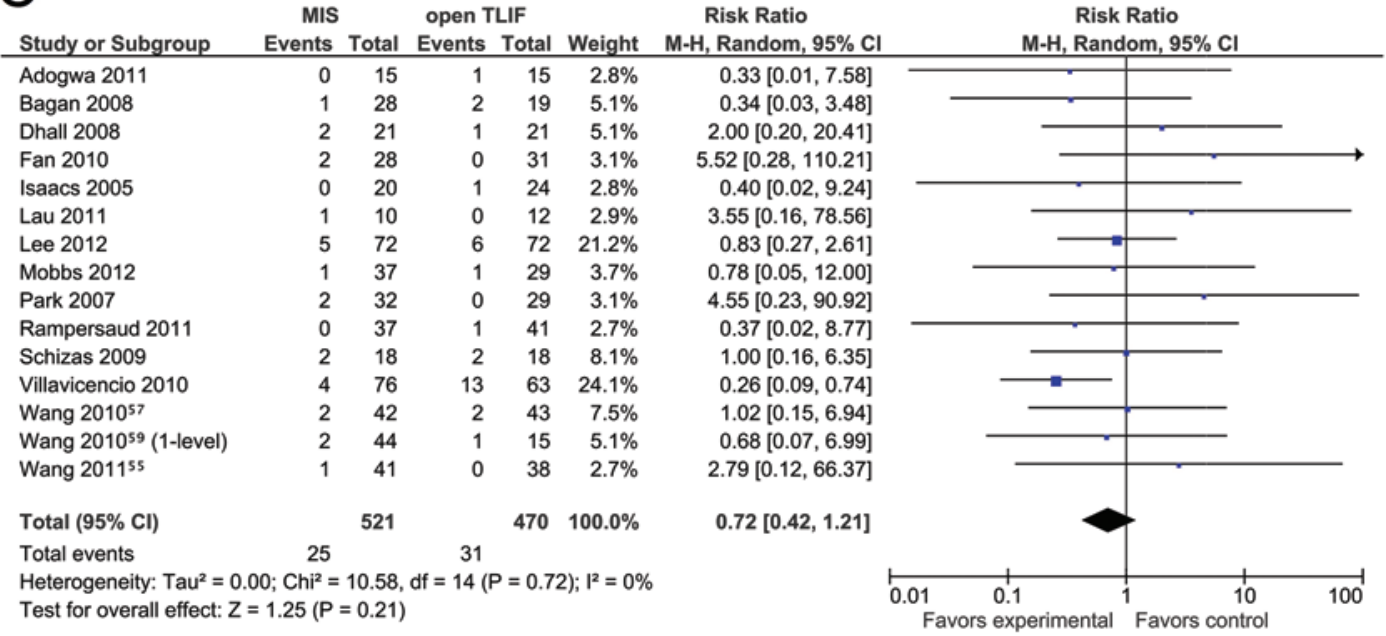

FIG. 3. Forest plots illustrating individual study and pooled RRs in MIS versus open cohorts for surgical complications, including dural tears (A), all infections (B), and all other surgical complications (C; including graft or screw malposition, new neurological deficit or nerve injury, and surgical site hematoma). $\mathrm{df}=$ degrees of freedom; $\mathrm{M}-\mathrm{H}=$ Mantel-Haenszel. Figure is available in color online only. 


\begin{tabular}{|c|c|c|c|c|c|c|c|c|c|}
\hline Study or Subgroup & $\begin{array}{r}\text { MIS } \\
\text { Events }\end{array}$ & Total & $\begin{array}{l}\text { open TL } \\
\text { Events }\end{array}$ & $\begin{array}{l}\text { LIF } \\
\text { Total }\end{array}$ & Weight & $\begin{array}{c}\text { Risk Ratio } \\
\text { M-H, Random, } 95 \% \mathrm{Cl} \\
\end{array}$ & $\begin{array}{r}\text { Risk } \\
\text { M-H, Rand } \\
\end{array}$ & $\begin{array}{l}\text { Ratio } \\
\text { dom, } 95 \% \mathrm{Cl}\end{array}$ & \\
\hline Adogwa 2011 & 0 & 15 & 1 & 15 & $7.9 \%$ & $0.33[0.01,7.58]$ & & & \\
\hline Dhall 2008 & 3 & 21 & 1 & 21 & $15.2 \%$ & $3.00[0.34,26.56]$ & & & \\
\hline Harris 2011 & 0 & 30 & 1 & 21 & $7.7 \%$ & $0.24[0.01,5.54]$ & & & \\
\hline Lau 2011 & 1 & 10 & 0 & 12 & $8.0 \%$ & $3.55[0.16,78.56]$ & & & \\
\hline Lee 2012 & 1 & 72 & 1 & 72 & $10.0 \%$ & $1.00[0.06,15.68]$ & & & \\
\hline Mobbs 2012 & 0 & 37 & 2 & 29 & $8.5 \%$ & $0.16[0.01,3.17]$ & 4 & & \\
\hline Park 2007 & 4 & 32 & 2 & 29 & $25.1 \%$ & $1.81[0.36,9.17]$ & & & \\
\hline Villavicencio 2010 & 0 & 76 & 4 & 63 & $9.0 \%$ & $0.09[0.01,1.68]$ & $\leftarrow$ & & \\
\hline Wang $2010^{57}$ & 2 & 42 & 0 & 43 & $8.5 \%$ & $5.12[0.25,103.50]$ & & & \\
\hline Total $(95 \% \mathrm{Cl})$ & & 335 & & 305 & $100.0 \%$ & $0.99[0.40,2.44]$ & & & \\
\hline Total events & 11 & & 12 & & & & & & \\
\hline $\begin{array}{l}\text { Heterogeneity: Tau } \\
\text { Test for overall effect }\end{array}$ & $\begin{array}{l}0.16 ; \mathrm{Ch}^{2}= \\
\mathrm{z}=0.03(\mathrm{P}\end{array}$ & $\begin{array}{l}=8.73, \\
=0.97\end{array}$ & df $=8(P$ & $=0.37$ & ); $1^{2}=8 \%$ & & $\begin{array}{ll}0.01 & 0.1 \\
\text { Favors experimental }\end{array}$ & $\begin{array}{l}1 \\
1\end{array} \frac{10}{\text { Favors control }}$ & 100 \\
\hline
\end{tabular}

FIG. 4. Forest plot illustrating individual study and pooled RRs in MIS versus open cohorts for reoperation for surgical complications. The line at 1 represents the line of no effect. Figure is available in color online only.

operative time, complication rates, and reoperation rates were similar, but they acknowledged that significant bias in patient selection may have contributed to their findings. Finally, the quality of studies was evaluated using the Journal of Bone and Joint Surgery criteria for assessment of methodological quality, with the strength of the evidence qualified as low. As a result, the authors concluded that further research would be likely to either change their observed results or their confidence in the results.

Although the current report exhibits a number of strengths compared with prior investigations, including its examination of the methodological quality of the included studies and inclusion of only comparative studies and meta-analysis of results pertaining to perioperative process measures, patient-reported outcomes, and complication rates, our study is still subject to several limitations. Regarding the quality of the included reports, all of the studies identified in our systematic review were given GRADE ratings of low or very low quality. One of the primary shortcomings of many of these studies relates to the lack of reporting of differentiated clinical outcomes in a heterogeneous patient population. . $^{2,8,9,22,25,29,35,37,42,43,47,54-56,58,59}$

In contrast to isthmic or degenerative spondylolisthesis, the criteria by which patients are diagnosed with degenerative disc disease or discogenic back pain are vague and poorly defined. ${ }^{61}$ As a result, heterogeneous patients with variable potential for treatment benefit are lumped together for the purpose of comparing surgical techniques. While diagnostic heterogeneity is less likely to influence perioperative outcomes due to similarities in surgical technique across diagnostic categories, clinical outcome of lumbar fusion is known to be dependent on primary diagnosis, with spondylolisthesis typically associated with the most favorable outcomes. ${ }^{14}$ Given the low to very low quality of the existing literature and seemingly small difference between the effect sizes of MIS versus open fusion, the diagnostic heterogeneity of the patient populations intrinsic to each study may represent a bias toward the null hypothesis.

Furthermore, the patient samples in these studies are small, ranging from 10 to 76 patients per treatment arm, and are often limited to nonconsecutive patients from a single institution, treated by a single surgeon. In addition, the decision to conduct open or MIS fusion was not randomized and was often dependent on a change in surgeon techniques, ${ }^{52}$ patient symptomatology ${ }^{59}$ or diagnosis, ${ }^{43}$ patient preference, , $, 13,21,22$ or payment status..$^{29,35}$ The selection bias introduced through failure to randomize patients introduces the probability that observed clinical differences in treatment groups are due to temporal shifts in outcomes,

\begin{tabular}{|c|c|c|c|c|c|c|c|c|c|}
\hline Study or Subgroup & \multicolumn{2}{|l|}{ MIS } & \multicolumn{2}{|c|}{ open TLIF } & Weight & $\begin{array}{c}\text { Risk Ratio } \\
\text { M-H, Random, } 95 \% \mathrm{Cl}\end{array}$ & \multicolumn{2}{|c|}{$\begin{array}{c}\text { Risk Ratio } \\
\text { M-H, Random, } 95 \% \mathrm{Cl}\end{array}$} & \\
\hline Bagan 2008 & 2 & 28 & 1 & 19 & $5.7 \%$ & $1.36[0.13,13.93]$ & & & \\
\hline Fan 2010 & 1 & 28 & 2 & 31 & $5.6 \%$ & $0.55[0.05,5.78]$ & & & \\
\hline Ghahreman 2010 & 1 & 25 & 5 & 27 & $7.2 \%$ & $0.22[0.03,1.72]$ & & & \\
\hline Harris 2011 & 1 & 30 & 0 & 21 & $3.1 \%$ & $2.13[0.09,49.86]$ & & & \\
\hline Isaacs 2005 & 1 & 20 & 6 & 24 & $7.5 \%$ & $0.20[0.03,1.53]$ & & & \\
\hline Lau 2011 & 2 & 10 & 3 & 12 & $12.4 \%$ & $0.80[0.16,3.88]$ & & & \\
\hline Lee 2012 & 1 & 72 & 2 & 72 & $5.5 \%$ & $0.50[0.05,5.39]$ & & & \\
\hline Mobbs 2012 & 1 & 37 & 6 & 29 & $7.3 \%$ & $0.13[0.02,1.03]$ & & & \\
\hline Peng 2009 & 0 & 29 & 3 & 29 & $3.6 \%$ & $0.14[0.01,2.65]$ & & & \\
\hline Rampersaud 2011 & 3 & 37 & 15 & 41 & $23.0 \%$ & $0.22[0.07,0.70]$ & & & \\
\hline Villavicencio 2010 & 3 & 76 & 1 & 63 & $6.2 \%$ & $2.49[0.27,23.32]$ & & & \\
\hline Wang $2010^{59}$ (2-level) & 1 & 8 & 3 & 7 & $7.5 \%$ & $0.29[0.04,2.21]$ & & & \\
\hline Wang $2011^{\text {ss }}$ & 1 & 41 & 2 & 38 & $5.5 \%$ & $0.46[0.04,4.91]$ & & & \\
\hline Total $(95 \% \mathrm{Cl})$ & & 441 & & 413 & $100.0 \%$ & $0.39[0.23,0.69]$ & & & \\
\hline Total events & 18 & & 49 & & & & & & \\
\hline $\begin{array}{l}\text { Heterogeneity: } \operatorname{Tau}^{2}=0 \\
\text { Test for overall effect: Z }\end{array}$ & $\begin{array}{l}\text { Do; } \mathrm{Chi}^{2}= \\
=3.29(\mathrm{P}\end{array}$ & $\begin{array}{l}9.09, \mathrm{~d} \\
=0.001\end{array}$ & if $=12(P$ & $=0.70$ & $; 1^{2}=0 \%$ & & 0.01 & 10 & 100 \\
\hline
\end{tabular}

FIG. 5. Forest plot of individual study and pooled RRs in MIS versus open cohorts for all medical complications. Values to the left of 1 favor MIS. Figure is available in color online only. 


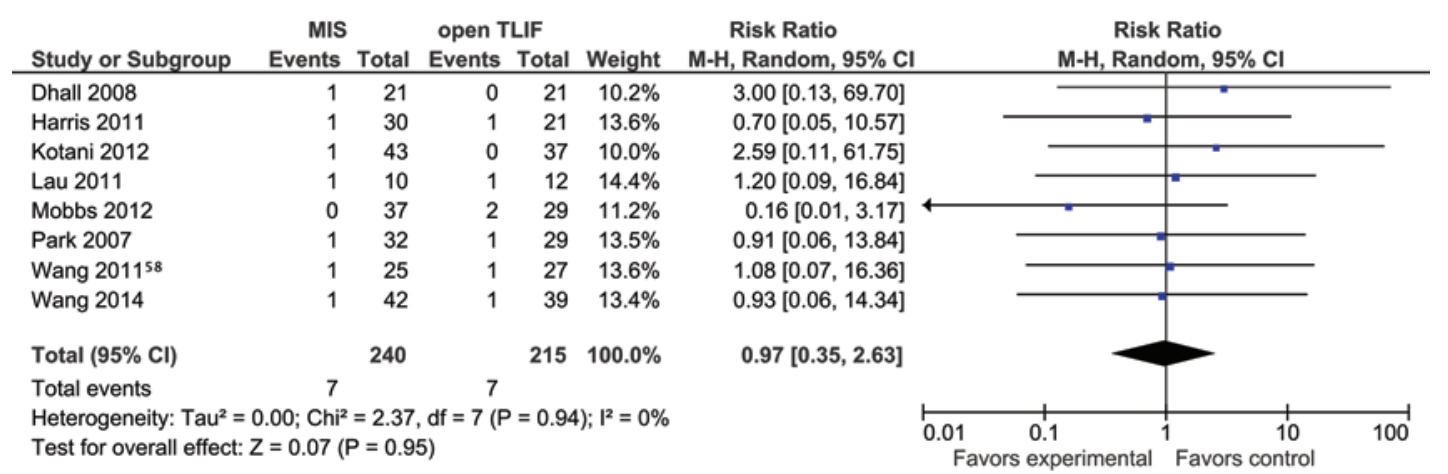

FIG. 6. Forest plot demonstrating individual study and pooled RRs for non-union in MIS versus open cohorts. The line at 1 represents the line of no effect. Figure is available in color online only.

systematic differences in patient care, severity of disease, and/or patient expectations.

It may also be the case that differences between the cohorts for variables associated with increased complication rates or reasons to choose open versus minimally invasive surgery may have contributed to the differences observed in this meta-analysis. Medical comorbidities, ${ }^{44}$ increased body mass index, ${ }^{6,18}$ and revision surgery ${ }^{39}$ have all been associated with increased surgical and medical complications in patients undergoing spine surgery, with minimally invasive spinal fusion being increasingly applied in these high-risk patients. ${ }^{19,34,45}$ Although we were unable to examine for differences due to lack of reporting of specific predictor variables in the majority of studies, we do not believe it likely that this would have significantly influenced our results. Articles that did report other demographic variables failed to show a statistically significant difference between open and MIS patients with respect to medical comorbidities, ${ }^{2,8,42}$ American Society of Anesthesiologists classification, ${ }^{9,35,41}$ Charlson Comorbidity Index, ${ }^{41,59}$ weight, $, 22,55$ body mass index, ${ }^{2,9,25,32,35,38,41,52}$ or revision versus primary surgery. $2,47,54$

In addition, a lack of clear diagnostic criteria for complications and the typically retrospective collection of adverse event data in those studies included in our metaanalysis of complication rates is likely to have biased our study results. ${ }^{28,40,48}$ Finally, although the combined sample size of this meta-analysis far surpasses any of the individual included studies, an a priori power calculation was not performed given the number of outcomes examined and the uncertainty of the between-study variance. ${ }^{53}$ Therefore, it remains possible that the number of nonsignificant comparisons between the open and MIS cohorts was due to insufficient power of our meta-analysis to detect a difference if one existed.

\section{Conclusions}

Our systematic review and meta-analysis of the results of comparative studies of open versus minimally invasive TLIF/PLIF for degenerative conditions has identified equivalent 2-year patient-reported clinical outcomes with improvements in perioperative measures including EBL, LOS, and total complication rates in patients undergoing MIS compared with open surgery. Although our ability to draw definitive conclusions regarding the safety and ef- fectiveness of this surgical technique are limited by the bias inherent to the current literature, these results provide compelling evidence in support of the need for future study of MIS versus open lumbar fusion in the form of either multicenter RCTs or multicenter observational studies incorporating valid, reliable, and responsive health-related quality of life instruments and a priori definitions of complications with rigorous diagnostic criteria to definitively address the question of the relative safety and effectiveness of minimally invasive TLIF/PLIF.

\section{Acknowledgments}

Dr. Rampersaud has received unrestricted research funding from the Toronto General and Western Hospital Foundation-Minimal Access Ambulatory Spine Surgery Research and Education Program.

\section{References}

1. Adogwa O, Parker SL, Bydon A, Cheng J, McGirt MJ: Comparative effectiveness of minimally invasive versus open transforaminal lumbar interbody fusion: 2-year assessment of narcotic use, return to work, disability, and quality of life. J Spinal Disord Tech 24:479-484, 2011

2. Bagan B, Patel N, Deutsch H, Harrop J, Sharan A, Vaccaro AR, et al: Perioperative complications of minimally invasive surgery (MIS): comparison of MIS and open interbody fusion techniques. Surg Technol Int 17:281-286, 2008

3. Brozek JL, Akl EA, Alonso-Coello P, Lang D, Jaeschke R, Williams JW, et al: Grading quality of evidence and strength of recommendations in clinical practice guidelines. Part 1 of 3. An overview of the GRADE approach and grading quality of evidence about interventions. Allergy 64:669-677, 2009

4. Carreon LY, Puno RM, Dimar JR II, Glassman SD, Johnson JR: Perioperative complications of posterior lumbar decompression and arthrodesis in older adults. J Bone Joint Surg Am 85-A:2089-2092, 2003

5. Cho KJ, Suk SI, Park SR, Kim JH, Kim SS, Choi WK, et al: Complications in posterior fusion and instrumentation for degenerative lumbar scoliosis. Spine (Phila Pa 1976) 32:2232-2237, 2007

6. De la Garza-Ramos R, Bydon M, Abt N, Sciubba DM, Wolinsky JP, Bydon A, et al: The impact of obesity on short- and long-term outcomes following lumbar fusion. Spine (Phila Pa 1976) [epub ahead of print], 2014

7. DerSimonian R, Laird N: Meta-analysis in clinical trials. Control Clin Trials 7:177-188, 1986

8. Dhall SS, Wang MY, Mummaneni PV: Clinical and radio- 
graphic comparison of mini-open transforaminal lumbar interbody fusion with open transforaminal lumbar interbody fusion in 42 patients with long-term follow-up. J Neurosurg Spine 9:560-565, 2008

9. Fan S, Hu Z, Zhao F, Zhao X, Huang Y, Fang X: Multifidus muscle changes and clinical effects of one-level posterior lumbar interbody fusion: minimally invasive procedure versus conventional open approach. Eur Spine J 19:316-324, 2010

10. Foley KT, Holly LT, Schwender JD: Minimally invasive lumbar fusion. Spine (Phila Pa 1976) 28 (15 Suppl):S26-S35, 2003

11. Fourney DR, Dettori JR, Norvell DC, Dekutoski MB: Does minimal access tubular assisted spine surgery increase or decrease complications in spinal decompression or fusion? Spine (Phila Pa 1976) 35 (9 Suppl):S57-S65, 2010

12. Garry R, Fountain J, Mason S, Hawe J, Napp V, Abbott J, et al: The eVALuate study: two parallel randomised trials, one comparing laparoscopic with abdominal hysterectomy, the other comparing laparoscopic with vaginal hysterectomy. BMJ 328:129, 2004

13. Ghahreman A, Ferch RD, Rao PJ, Bogduk N: Minimal access versus open posterior lumbar interbody fusion in the treatment of spondylolisthesis. Neurosurgery 66:296-304, 2010

14. Glassman SD, Carreon LY, Djurasovic M, Dimar JR, Johnson JR, Puno RM, et al: Lumbar fusion outcomes stratified by specific diagnostic indication. Spine J 9:13-21, 2009

15. Goldstein CL, Macwan K, Sundararajan K, Rampersaud YR: Comparative outcomes of minimally invasive surgery for posterior lumbar fusion: a systematic review. Clin Orthop Relat Res 472:1727-1737, 2014

16. Harris EB, Sayadipour A, Massey P, Duplantier NL, Anderson DG: Mini-open versus open decompression and fusion for lumbar degenerative spondylolisthesis with stenosis. Am J Orthop 40:E257-E261, 2011

17. Isaacs RE, Podichetty VK, Santiago P, Sandhu FA, Spears J, Kelly K, et al: Minimally invasive microendoscopy-assisted transforaminal lumbar interbody fusion with instrumentation. J Neurosurg Spine 3:98-105, 2005

18. Kalanithi PA, Arrigo R, Boakye M: Morbid obesity increases cost and complication rates in spinal arthrodesis. Spine (Phila Pa 1976) 37:982-988, 2012

19. Karikari IO, Grossi PM, Nimjee SM, Hardin C, Hodges TR, Hughes BD, et al: Minimally invasive lumbar interbody fusion in patients older than 70 years of age: analysis of periand postoperative complications. Neurosurgery 68:897-902, 2011

20. Karikari IO, Isaacs RE: Minimally invasive transforaminal lumbar interbody fusion: a review of techniques and outcomes. Spine (Phila Pa 1976) 35 (26 Suppl):S294-S301, 2010

21. Kotani Y, Abumi K, Ito M, Sudo H, Abe Y, Minami A: Midterm clinical results of minimally invasive decompression and posterolateral fusion with percutaneous pedicle screws versus conventional approach for degenerative spondylolisthesis with spinal stenosis. Eur Spine J 21:1171-1177, 2012

22. Lau D, Lee JG, Han SJ, Lu DC, Chou D: Complications and perioperative factors associated with learning the technique of minimally invasive transforaminal lumbar interbody fusion (TLIF). J Clin Neurosci 18:624-627, 2011

23. Lee JC, Jang HD, Shin BJ: Learning curve and clinical outcomes of minimally invasive transforaminal lumbar interbody fusion: our experience in 86 consecutive cases. Spine (Phila Pa 1976) 37:1548-1557, 2012

24. Lee KH, Yeo W, Soeharno H, Yue WM: Learning curve of a complex surgical technique: minimally invasive transforaminal lumbar interbody fusion (MIS TLIF). J Spinal Disord Tech 27:E234-E240, 2014

25. Lee KH, Yue WM, Yeo W, Soeharno H, Tan SB: Clinical and radiological outcomes of open versus minimally inva- sive transforaminal lumbar interbody fusion. Eur Spine J 21:2265-2270, 2012

26. Martin BI, Deyo RA, Mirza SK, Turner JA, Comstock BA, Hollingworth W, et al: Expenditures and health status among adults with back and neck problems. JAMA 299:656-664, 2008

27. McGirt MJ, Parker SL, Lerner J, Engelhart L, Knight T, Wang MY: Comparative analysis of perioperative surgical site infection after minimally invasive versus open posterior/ transforaminal lumbar interbody fusion: analysis of hospital billing and discharge data from 5170 patients. J Neurosurg Spine 14:771-778, 2011

28. Mirza SK, Deyo RA, Heagerty PJ, Turner JA, Lee LA, Goodkin R: Towards standardized measurement of adverse events in spine surgery: conceptual model and pilot evaluation. BMC Musculoskelet Disord 7:53, 2006

29. Mobbs RJ, Sivabalan P, Li J: Minimally invasive surgery compared to open spinal fusion for the treatment of degenerative lumbar spine pathologies. J Clin Neurosci 19:829-835, 2012

30. Moher D, Liberati A, Tetzlaff J, Altman DG : Preferred reporting items for systematic reviews and meta-analyses: the PRISMA statement. J Clin Epidemiol 62:1006-1012, 2009

31. Neyeloff JL, Fuchs SC, Moreira LB: Meta-analyses and forest plots using a Microsoft Excel spreadsheet: Step-by-step guide focusing on descriptive data analysis. BMC Res Notes 5:52, 2012

32. Ntoukas V, Müller A: Minimally invasive approach versus traditional open approach for one level posterior lumbar interbody fusion. Minim Invasive Neurosurg 53:21-24, 2010

33. Pace KT, Dyer SJ, Stewart RJ, Honey RJ, Poulin EC, Schlachta CM, et al: Health-related quality of life after laparoscopic and open nephrectomy. Surg Endosc 17:143-152, 2003

34. Park P, Upadhyaya C, Garton HJ, Foley KT: The impact of minimally invasive spine surgery on perioperative complications in overweight or obese patients. Neurosurgery 62:693699, 2008

35. Park Y, Ha JW: Comparison of one-level posterior lumbar interbody fusion performed with a minimally invasive approach or a traditional open approach. Spine (Phila Pa 1976) 32:537-543, 2007

36. Parker SL, Adogwa O, Witham TF, Aaronson OS, Cheng J, McGirt MJ: Post-operative infection after minimally invasive versus open transforaminal lumbar interbody fusion (TLIF): literature review and cost analysis. Minim Invasive Neurosurg 54:33-37, 2011

37. Pelton MA, Phillips FM, Singh K: A comparison of perioperative costs and outcomes in patients with and without workers' compensation claims treated with minimally invasive or open transforaminal lumbar interbody fusion. Spine (Phila Pa 1976) 37:1914-1919, 2012

38. Peng CW, Yue WM, Poh SY, Yeo W, Tan SB: Clinical and radiological outcomes of minimally invasive versus open transforaminal lumbar interbody fusion. Spine (Phila Pa 1976) 34:1385-1389, 2009

39. Proietti L, Scaramuzzo L, Schiro' GR, Sessa S, Logroscino CA: Complications in lumbar spine surgery: A retrospective analysis. Indian J Orthop 47:340-345, 2013

40. Rampersaud YR: Commentary: complications in spine surgery: "the devil is in the details". Spine J 12:207-208, 2012

41. Rampersaud YR, Gray R, Lewis SJ, Massicotte EM, Fehlings MG: Cost-utility analysis of posterior minimally invasive fusion compared with conventional open fusion for lumbar spondylolisthesis. SAS J 5:29-35, 2011

42. Scheufler KM, Dohmen H, Vougioukas VI: Percutaneous transforaminal lumbar interbody fusion for the treatment of degenerative lumbar instability. Neurosurgery 60 (4 Suppl 2):203-213, 2007 
43. Schizas C, Tzinieris N, Tsiridis E, Kosmopoulos V: Minimally invasive versus open transforaminal lumbar interbody fusion: evaluating initial experience. Int Orthop 33:16831688,2009

44. Schoenfeld AJ, Ochoa LM, Bader JO, Belmont PJ Jr: Risk factors for immediate postoperative complications and mortality following spine surgery: a study of 3475 patients from the National Surgical Quality Improvement Program. J Bone Joint Surg Am 93:1577-1582, 2011

45. Selznick LA, Shamji MF, Isaacs RE: Minimally invasive interbody fusion for revision lumbar surgery: technical feasibility and safety. J Spinal Disord Tech 22:207-213, 2009

46. Silva PS, Pereira P, Monteiro P, Silva PA, Vaz R: Learning curve and complications of minimally invasive transforaminal lumbar interbody fusion. Neurosurg Focus 35(2):E7, 2013

47. Starkweather AR, Witek-Janusek L, Nockels RP, Peterson J, Mathews HL: The multiple benefits of minimally invasive spinal surgery: results comparing transforaminal lumbar interbody fusion and posterior lumbar fusion. J Neurosci Nurs 40:32-39, 2008

48. Street JT, Lenehan BJ, DiPaola CP, Boyd MD, Kwon BK, Paquette SJ, et al: Morbidity and mortality of major adult spinal surgery. A prospective cohort analysis of 942 consecutive patients. Spine J 12:22-34, 2012

49. Stroup DF, Berlin JA, Morton SC, Olkin I, Williamson GD, Rennie D, et al: Meta-analysis of observational studies in epidemiology: a proposal for reporting. Meta-analysis Of Observational Studies in Epidemiology (MOOSE) group. JAMA 283:2008-2012, 2000

50. Thomsen K, Christensen FB, Eiskjaer SP, Hansen ES, Fruensgaard S, Bünger CE: 1997 Volvo Award winner in clinical studies. The effect of pedicle screw instrumentation on functional outcome and fusion rates in posterolateral lumbar spinal fusion: a prospective, randomized clinical study. Spine (Phila Pa 1976) 22:2813-2822, 1997

51. Topçu O, Karakayali F, Kuzu MA, Ozdemir S, Erverdi N, Elhan A, et al: Comparison of long-term quality of life after laparoscopic and open cholecystectomy. Surg Endosc 17:291-295, 2003

52. Tsutsumimoto T, Shimogata M, Ohta H, Misawa H: Miniopen versus conventional open posterior lumbar interbody fusion for the treatment of lumbar degenerative spondylolisthesis: comparison of paraspinal muscle damage and slip reduction. Spine (Phila Pa 1976) 34:1923-1928, 2009

53. Valentine JC, Pigott TD, Rothstein HR: How many studies do you need? A primer on statistical power for meta-analysis. J Educ Behav Stat 35:215-247, 2010

54. Villavicencio AT, Burneikiene S, Roeca CM, Nelson EL, Mason A: Minimally invasive versus open transforaminal lumbar interbody fusion. Surg Neurol Int 1:12, 2010

55. Wang HL, Lü FZ, Jiang JY, Ma X, Xia XL, Wang LX: Minimally invasive lumbar interbody fusion via MAST Quadrant retractor versus open surgery: a prospective randomized clinical trial. Chin Med J (Engl) 124:3868-3874, 2011

56. Wang J, Zhou Y, Zhang ZF, Li CQ Zheng WJ, Liu J: Comparison of clinical outcome in overweight or obese patients after minimally invasive versus open transforaminal lumbar interbody fusion. J Spinal Disord Tech 27:202-206, 2014

57. Wang J, Zhou Y, Zhang ZF, Li CQ, Zheng WJ, Liu J: Comparison of one-level minimally invasive and open transforaminal lumbar interbody fusion in degenerative and isthmic spondylolisthesis grades 1 and 2. Eur Spine J 19:1780-1784, 2010

58. Wang J, Zhou Y, Zhang ZF, Li CQ, Zheng WJ, Liu J: Minimally invasive or open transforaminal lumbar interbody fusion as revision surgery for patients previously treated by open discectomy and decompression of the lumbar spine. Eur Spine J 20:623-628, 2011

59. Wang MY, Cummock MD, Yu Y, Trivedi RA: An analysis of the differences in the acute hospitalization charges following minimally invasive versus open posterior lumbar interbody fusion. J Neurosurg Spine 12:694-699, 2010

60. Wu RH, Fraser JF, Härtl R: Minimal access versus open transforaminal lumbar interbody fusion: meta-analysis of fusion rates. Spine (Phila Pa 1976) 35:2273-2281, 2010

61. Zhang YG, Guo TM, Guo X, Wu SX: Clinical diagnosis for discogenic low back pain. Int J Biol Sci 5:647-658, 2009

\section{Disclosures}

Dr. Goldstein is a committee member for AOSpine North America. Dr. Rampersaud is a consultant for Medtronic.

\section{Author Contributions}

Conception and design: Rampersaud, Goldstein. Acquisition of data: Rampersaud, Goldstein, Macwan. Analysis and interpretation of data: Rampersaud, Goldstein, Sundararajan. Drafting the article: Goldstein. Critically revising the article: Rampersaud, Goldstein, Macwan. Reviewed submitted version of manuscript: Goldstein, Macwan, Sundararajan. Statistical analysis: Sundararajan.

\section{Supplemental Information}

\section{Previous Presentation}

Portions of this study were presented in abstract form as proceedings of the 2013 Canadian Spine Society Annual Scientific Conference and in poster form at the 2013 North American Spine Society Annual Meeting.

\section{Correspondence}

Y. Raja Rampersaud, Division of Orthopaedics, University of Toronto, Toronto Western Hospital, 399 Bathurst St., EW 1-441, Toronto, ON M5T 2S8, Canada. email: raja.rampersaud@uhn. on.ca. 